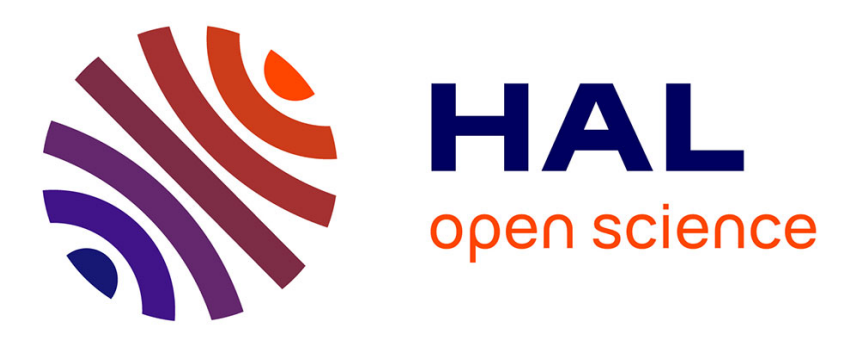

\title{
Damage Mechanics Modelling of the shear nonlinear behavior of Nomex honeycomb core. Application to sandwich beams
}

Juan de Dios Rodriguez-Ramirez, Bruno Castanié, Christophe Bouvet

\section{To cite this version:}

Juan de Dios Rodriguez-Ramirez, Bruno Castanié, Christophe Bouvet. Damage Mechanics Modelling of the shear nonlinear behavior of Nomex honeycomb core. Application to sandwich beams. Mechanics of Advanced Materials and Structures, 2020, 27 (1), pp.0. 10.1080/15376494.2018.1472351 . hal01880448

\section{HAL Id: hal-01880448 \\ https://hal.science/hal-01880448}

Submitted on 29 Jan 2019

HAL is a multi-disciplinary open access archive for the deposit and dissemination of scientific research documents, whether they are published or not. The documents may come from teaching and research institutions in France or abroad, or from public or private research centers.
L'archive ouverte pluridisciplinaire HAL, est destinée au dépôt et à la diffusion de documents scientifiques de niveau recherche, publiés ou non, émanant des établissements d'enseignement et de recherche français ou étrangers, des laboratoires publics ou privés. 


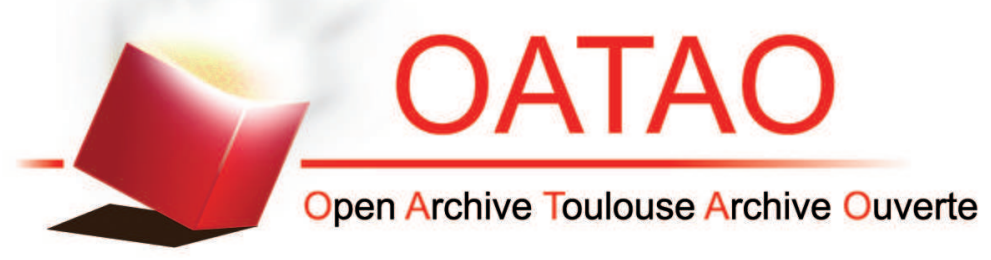

\section{Open Archive Toulouse Archive Ouverte (OATAO)}

OATAO is an open access repository that collects the work of some Toulouse researchers and makes it freely available over the web where possible.

This is an author's version published in: https://oatao.univ-toulouse.fr/21828

Official URL: https://doi.org/10.1080/15376494.2018.1472351

\section{To cite this version :}

Rodríguez Ramírez, Juan de Dios and Castanié, Bruno and Bouvet, Christophe Damage Mechanics Modelling of the shear nonlinear behavior of Nomex honeycomb core. Application to sandwich beams. (2018) Mechanics of Advanced Materials and Structures. ISSN 1537-6494

Any correspondence concerning this service should be sent to the repository administrator: tech-oatao@listes-diff.inp-toulouse.fr 


\title{
Damage Mechanics Modelling of the shear nonlinear behavior of Nomex honeycomb core. Application to sandwich beams
}

\author{
Juan de Dios Rodríguez-Ramírez, Bruno Castanié, and Christophe Bouvet \\ Institut Clément Ader (ICA), Université de Toulouse, CNRS UMR 5312 - INSA, ISAE-Supaéro - Mines Albi - UPS, Toulouse, France
}

\begin{abstract}
In this work, a modelling strategy based on damage mechanics is presented for Nomex honeycomb core. The proposed approach is based on the experimental analysis presented by the authors in [1] and consists of the decoupled modelling of the buckling and collapse of cells for the HRH-78 Nomex honeycomb core with two damage parameters. The proposed approach shows good agreement with the experimental tests. The computational cost is low, proving the efficacy of this technique. This strategy may avoid using full $3 \mathrm{D}$ models that mimic the real shape and is a step toward a full compression/shear nonlinear model for honeycomb core.
\end{abstract}

KEYWORDS Sandwich structures; sandwich testing; shear buckling; damage mechanics; honeycomb

\section{Introduction}

Honeycomb cores are used for sandwich construction in aeronautics because they are very light, have excellent resistance to fatigue, and allow smooth skins to be obtained [2]. Applications of nonmetallic honeycomb cores include helicopter panel structures [3], cabin interiors of some aeroplanes, landing gear doors, and for some business jets fuselage [4], [5]. These nonmetallic cores are mostly made of Nomex paper that is glued and then expanded to create the honeycomb cells. The resulting grid is then dipped in phenolic resin and cured to increase its resistance.

The mechanical properties of these cores are important for the design of sandwich panels and they can be obtained by following normalized tests given in standards like ASTM C365 or C273 to determine their resistance to compression or shear stress. Since the behavior of honeycomb structures is complex, many of its aspects have been investigated separately. Since the early 1960 's, considerable research has been carried out on the crushing behavior of these honeycomb cores for energy absorption, using analytical approaches [6], [7]. With the development of computer technology and FEA software, it is now possible to create very refined models to analyse the mechanical behavior of the honeycomb structure, and researchers have used implicit and explicit codes to study several complex aspects, such as the effect of borders and imperfections on the cell walls [8], [9], the crushing and post impact behavior [10]-[12], inserts [13]-[15], the buckling of the cells in three point tests [16], [17], and the debonding of the cell walls [18], among many other phenomena.

It has become clear in the literature that, as the modelling of honeycomb cores has gained in importance, the number of features that have to be included into the models has also increased, whence a need for very high levels of expertise and long development times. This is not surprising, considering that the aim of the models developed for research purposes is to capture the behavior of the cells very precisely, without paying too much attention to the simulation time, which becomes a secondary parameter. However, these very detailed models are not suitable for industry, where very large simulations are run and it is not practical to implement such detailed models. Instead, the honeycomb cores are modelled as isotropic or orthotropic continuum materials with strength kept within the linear proportional limit to avoid dealing with the structural nonlinear effects. This simplification is very debatable. Also, the shear strength of the honeycomb core is underestimated, leading to oversizing.

Other researchers have developed an approach that captures the overall nonlinear behavior of the honeycomb core and could be simple enough to be implemented by industry. They have proved that, by understanding the structural behavior of the hexagonal cell, it is possible to propose a simplified discrete model that captures the global nonlinear behavior of the honeycomb core under compression with very accurate results [10], [11], [19], [20]. However, in the literature, there are no works focusing on how to use the same strategy to model the nonlinear shear behavior of a honeycomb structure.

Nevertheless, recently, a detailed study of the shear behavior of the HRH-78 Nomex honeycomb core was made through experimental and numerical modeling [1]. The authors described the general behavior of the honeycomb core and the shear buckling of the cells and it was proved that the nonlinear response of the honeycomb core and the buckling evolution of the cells were strongly influenced by the boundary conditions.

Considering all the information mentioned above, the purpose of the present research is to provide a simple but accurate strategy for modeling the honeycomb core for the shear case, starting from the observations made in [1] as they are very helpful to understand the general aspects of the structural behavior of hexagonal cells under shear forces. 


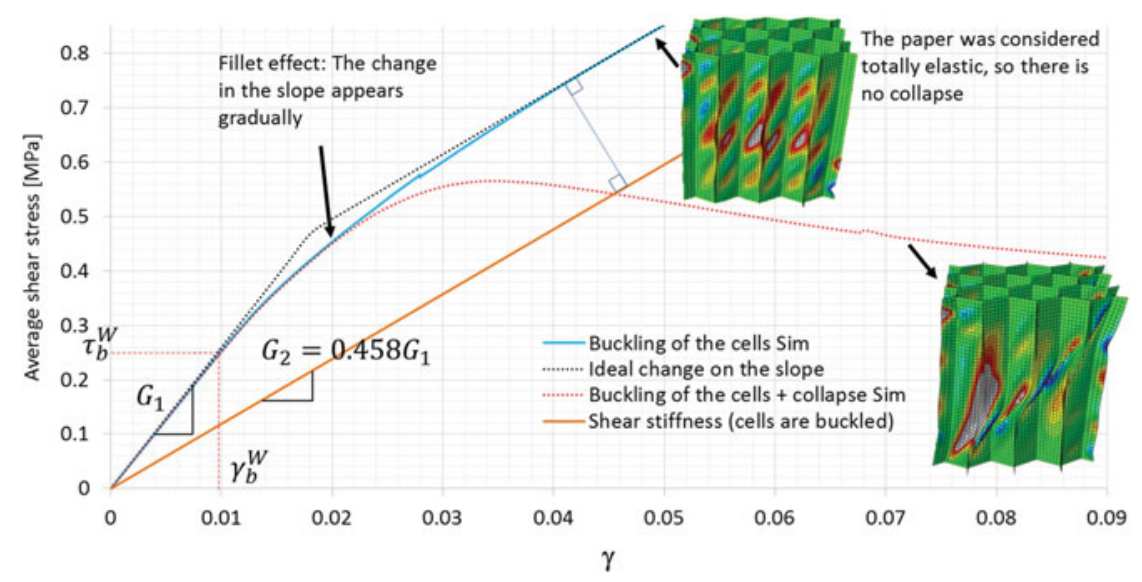

Figure 1. Change on the shear stiffness of the structure: curves of "Elastic buckling" of the cells vs. "buckling \& collapse" of the cells in the W direction. [1].

\section{Shear behavior of honeycomb cores}

In this section, the main aspects of the phenomenological description of the honeycomb core presented in [1] are discussed. When the honeycomb structure is subjected to shear loads, the overall nonlinear response of the structure can be explained by two different phenomenological stages: an initial buckling and the final collapse of the cells. This is very similar for the $\mathrm{W}$ and $\mathrm{L}$ directions.

\subsection{Buckling of the cells}

The first stage consists of the formation of local small buckles that reduce the overall stiffness of the honeycomb structure. This stage is elastically reversible, i.e., there is no structural damage. The cells are buckled in a stable configuration and the behavior of the honeycomb structure is nonlinear but remains elastic.

The buckling of the cells was also studied numerically, considering the hypothesis that the collapse of the cells was caused by the plasticity and breaking of the Nomex paper. Thus, to isolate the effect of buckling from the collapse, the numerical simulation considered the wall material to be totally elastic. The postbuckling response of the structure could be considered elastic (Figure 1). The fillet effect between the initial and postbuckling state could be explained by the fact that the cells did not necessarily all buckle in the same way. It was detected that the cells started to buckle at $\tau_{b}^{W}=0.25 \mathrm{MPa}\left(\gamma_{b}^{W}=0.0096\right)$.

By taking the hypothesis that the postbuckling response is elastic, it is possible to estimate the reduction of the shear stiffness of the structure once the cells are buckled. For very large deformations, the final shear stiffness of the structure is equal to the postbuckling slope of curve and $G_{2}=0.485 G_{1}$.

The F.E. model of Figure 1 was used to perform the same analysis for cells oriented along the $\mathrm{L}$ direction. The reduction of the shear stiffness was calculated from $G_{2}=0.584 G_{1}$, and it was also possible to determine that the buckling of the cells started at $\tau_{b}^{L}=0.47 \mathrm{MPa}\left(\gamma_{b}^{L}=0.014\right)$.

\subsection{Collapse of the cells}

The second stage is the collapse of the cells, which is characterized by the cells losing the ability to support larger loads. At this point the vertical vertices of the cells no longer remain straight but fold, leaving a residual strength apparently caused by the tearing of the paper. At this stage, weaker cells collapse earlier and stronger ones later. This is shown in Figure 2, where the

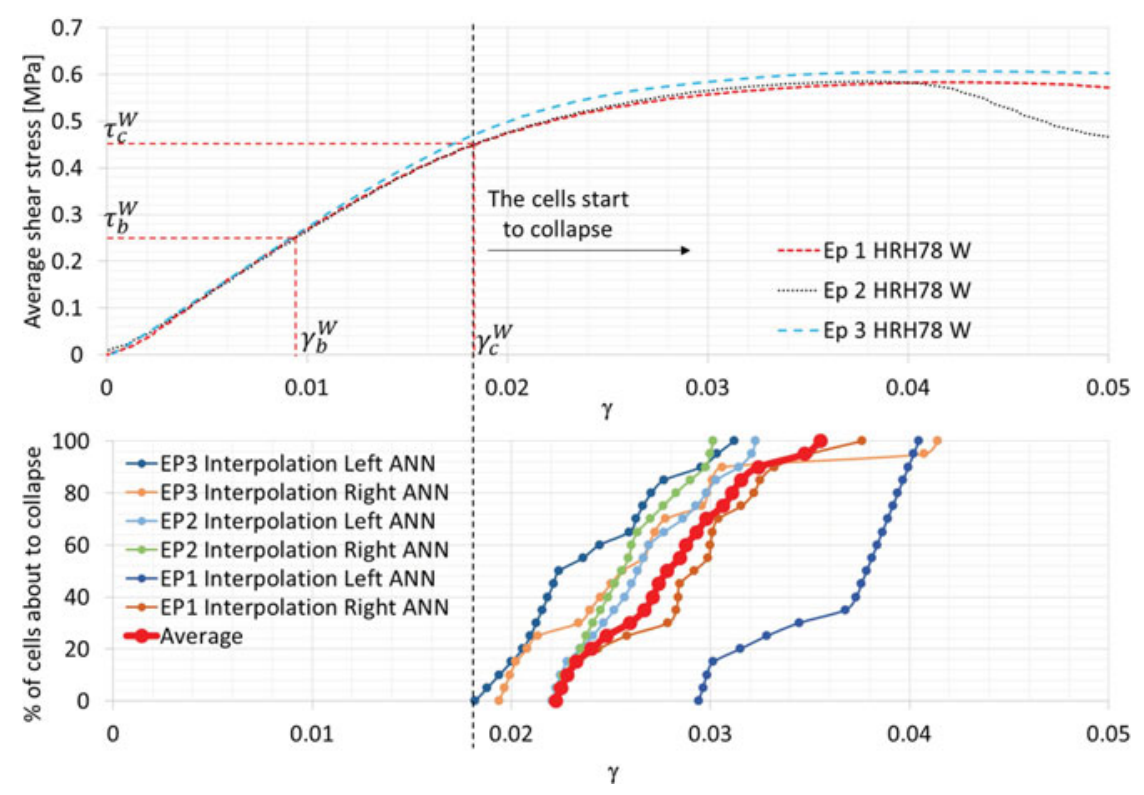

Figure 2. Detection of the collapse of the cells in the W direction through an ANN [1]. 


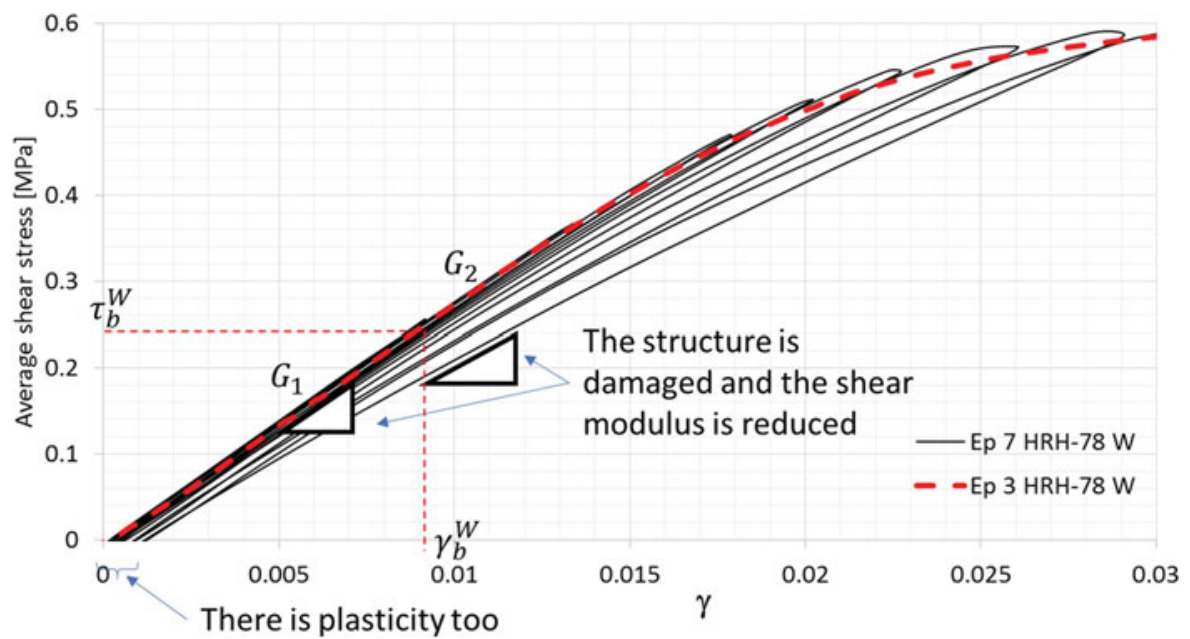

Figure 3. Incremental cyclic testing of the HRH-78 core: damaged shear behavior of the honeycomb structure [1].

percentage of cells that were about to buckle increases gradually with gamma. These curves were determined in [1] where an Artificial Neural Network (ANN) was developed to detect the collapse of the cells from the data collected by a 3D-DIC that was used to record the experiments.

This collapse stage takes place once the cells have buckled due to geometric imperfections, for example, variations in the thickness of the walls or the size and localization of deformations on the wall. This study was only performed for the $\mathrm{W}$ direction but a similar scenario should describe the collapse of the cells oriented along the $\mathrm{L}$ direction.

\section{Modeling of shear nonlinear behavior of HRH-78}

In this section a strategy for modeling the honeycomb structure is presented. First, the influence of the initial defects is discussed, then the modeling of both the initial buckling and the collapse stages are incorporated using a statistical approach.

In [1], it was stated that buckling and collapse of the cells were two different stages. In this work, it is considered that a superposition of the two stages should describe the complete behavior of the honeycomb core for the $\mathrm{W}$ and $\mathrm{L}$ directions.

The first observation is that, once the cells have buckled or collapsed, the structure shear stiffness is permanently reduced because of the plasticity and tearing of the Nomex paper, as in Figure 3 . This occurs similarly in the L direction too.
Secondly, the fact that the cells collapse gradually (presumably due to initial imperfections) can be described by a statistical distribution, where the weaker cells collapse before the stronger ones. In Figure 4a) a Weibull probability distribution function is used to fit the average experimental result for the collapsing cells and correlation is good. The probability density (which is similar to the classical normal distribution of defects) is shown in blue.

Both observations indicate that it is possible to use a statistical approach to describe the buckling and collapse stages and, also, that a continuum damage approach could be suitable to describe the behavior of Figure 3, making an analogy with the modeling of CFRP where statistical approaches are used to describe the breaking of fibres of different strengths, for instance [21].

\subsection{Initial buckling}

As explained before, as $\gamma$ increases, the final stiffness is reduced to $45.8 \%$ and $58.4 \%$ of the initial shear modulus for the $\mathrm{W}$ and $\mathrm{L}$ directions, respectively. It is also known that the cells start to buckle at $\gamma_{b}^{W}=0.0096\left(\tau_{b}^{W}=0.25 \mathrm{MPa}\right)$ and $\gamma_{b}^{L}=0.014$ $\left(\tau_{b}^{L}=0.47 \mathrm{MPa}\right)$ for the $\mathrm{W}$ and $\mathrm{L}$ directions respectively. Using the previous information, Eq. (1) is proposed to describe the damage of the honeycomb structure.

$$
D_{b}=A_{b}\left(1-e^{-\left\langle\frac{\gamma-\gamma_{b}}{\lambda_{b}}\right)^{k_{b}}}\right)
$$

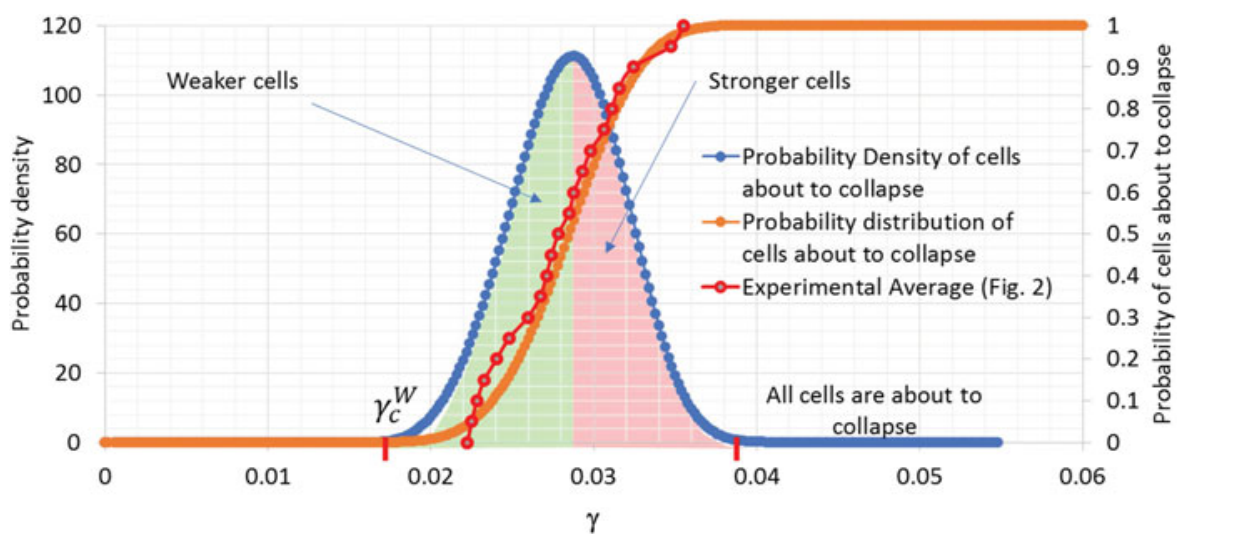

Figure 4. Fitting of the curve of percentage of cells about to buckle with a probability distribution function; the probability density is shown in blue. [1]. 


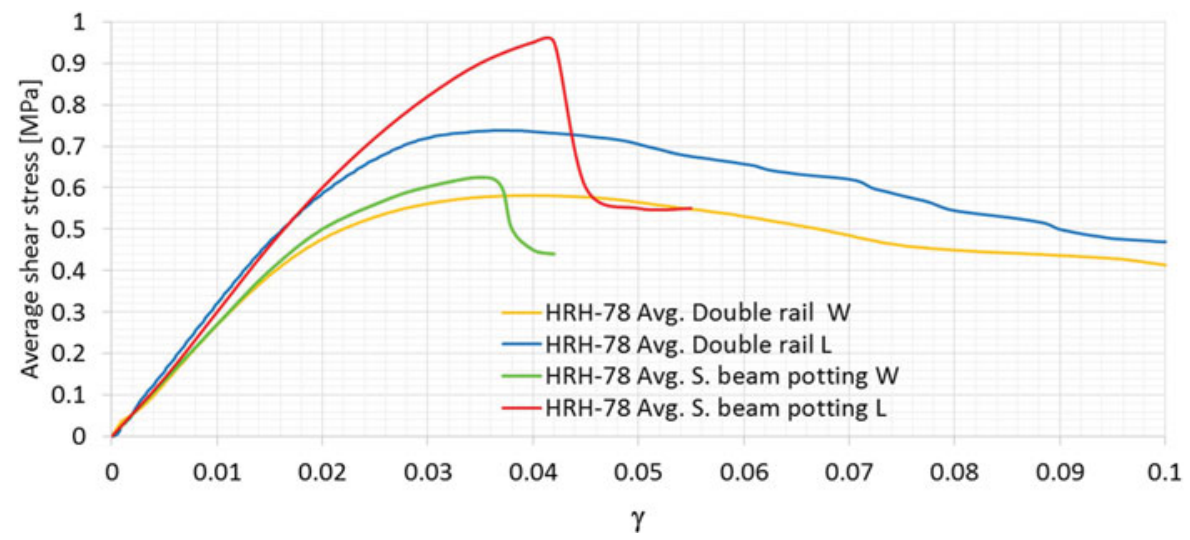

Figure 5. Average curves of "double rail tests" vs. "sandwich beam with potting at the borders". [1].

where $A_{b}$ represents the final stiffness reduction of the buckled honeycomb, $\gamma_{\mathrm{b}}$ is the shear strain that causes the buckling of the cells and thus the start of the nonlinear behavior. The parameters $A_{b}^{W}, A_{b}^{L}$ and $\gamma_{b}^{W}, \gamma_{b}^{L}$ have already been determined, while $\lambda_{b}^{W}$, $\lambda_{b}^{L}$ and $K_{b}^{W}, K_{b}^{L}$ are chosen to fit the honeycomb response with totally elastic walls. (See Table 1 and Figure 1).

\subsection{Collapse of the cells}

Modeling the collapse of the cells may not be very simple because the nonlinear response of the honeycomb core is strongly influenced by the boundary conditions of the cells. As stated in [1], even the shear strength of the core can be increased by up to $35 \%$ by stabilizing the cells laterally.

Table 1. Values used to fit the experimental curves of the HRH-78 tests.

\begin{tabular}{llll}
\hline & & W direction & L direction \\
\hline Initial buckling stage & $\mathrm{Ab}$ & 0.458 & 0.584 \\
& $\lambda_{b}$ & 0.029 & 0.04 \\
& $\gamma_{\mathrm{b} 0}$ & 0.0096 & 0.014 \\
Collapse stage & $k_{b}$ & 1 & 1 \\
& $\mathrm{Ac}$ & 0.85 & 0.85 \\
& $\lambda_{c}$ & 0.044 & 0.046 \\
& $\gamma_{c 0}$ & 0.018 & 0.018 \\
& $k_{c}$ & 1.9 & 1.45 \\
\hline
\end{tabular}

More specifically, it was proved that the response of rail testing and a three-point test was not the same for the nonlinear response. For the three-point bending test on a beam, the loss of load-bearing capacity of the cells was caused by their apparently dramatic collapse (at $\gamma=0.05$ ) while, for the rail tests, the reduction of the load bearing capacity was caused by a combination of tearing of the Nomex paper and collapse of the cells (see Figures 5 and 6) [1].

This is explained by the fact that the beam testing allows the cells to collapse by groups as the shear deformation is concentrated where the first cells collapsed (see Figure 14). Also, the collapsing and ripping of the paper occurs almost simultaneously in the vertical orientation of the cells, leading to a sudden failure and tearing of the paper, which leaves a residual shear stiffness (Figure 6).

On the other hand, the rail test skins impose the same displacement on all the cells. Consequently all of them are subjected to the same shear deformation, leading to a very slow reduction of the shear strength since the cells are being torn almost in the direction orthogonal to the cells.

For this reason, the modeling of the collapse stage with different boundary conditions presents different behaviors, and therefore they should be separated.

Here, a general approach to modeling the collapse phase is presented. It is assumed that the cells collapse gradually due to

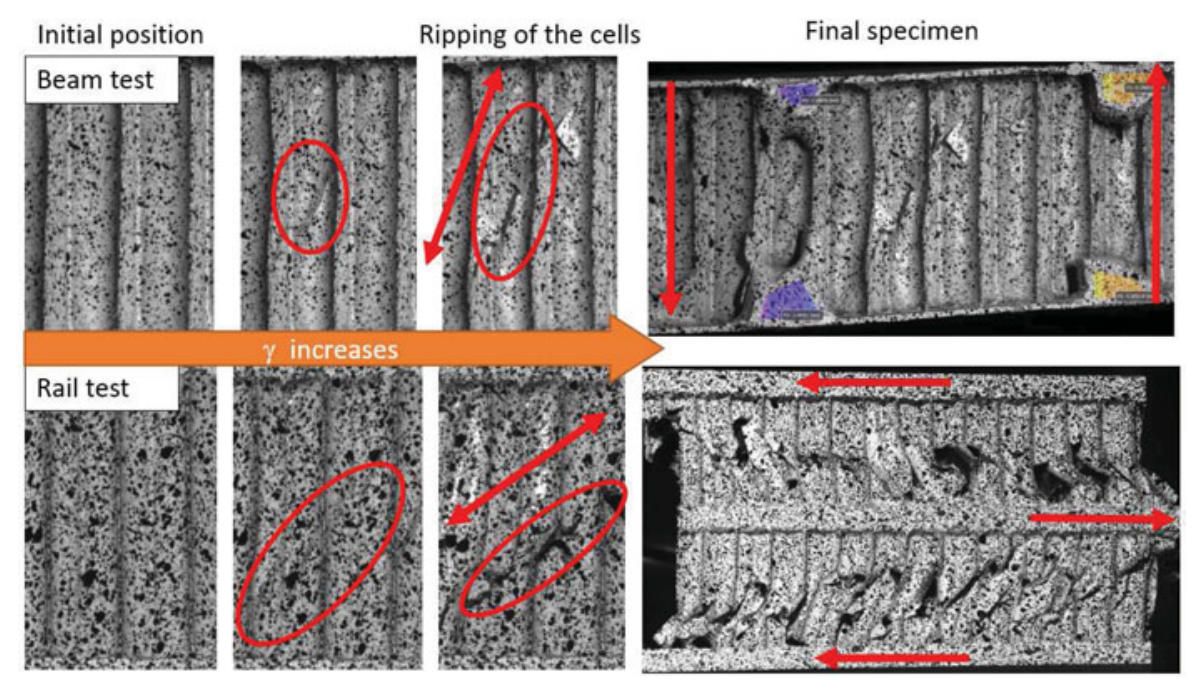

Figure 6. Comparison of cell ripping in $3 \mathrm{pt}$. bending test with potting resin at the borders and a double rail test. [1]. 

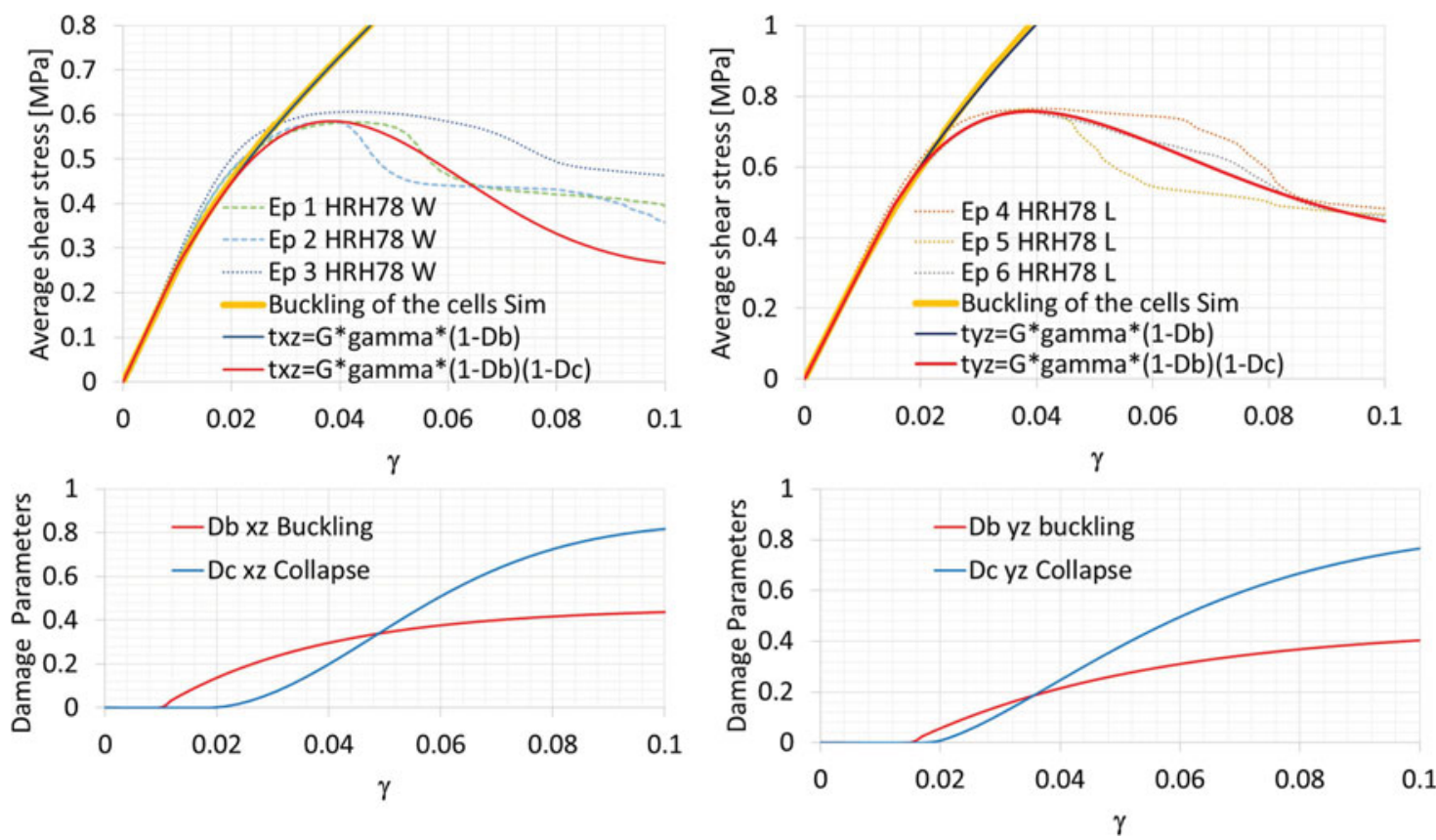

Figure 7. Fitting of the experimental rail shear testing curves of the HRH-78 in the $\mathrm{W}$ and $\mathrm{L}$ directions using the proposed CDM approach.

fabrication defects and this is represented by a Weibull distribution function. Also, we suppose that the loss of ability to support loads after the collapse of the cells can be represented with a coefficient $A_{c}$. If $A_{c}=0$ there is no collapse but if $A_{c}=1$ then the cells' capability to support any load is totally lost. So, the residual stiffness can be represented by $1-A_{c}$. Both rail and stabilized collapse behavior should be described within this interval (Eq. 2).

$$
D_{c}=A_{c}\left(1-e^{-\left\langle\frac{\gamma-\gamma_{c}}{\lambda_{c}}\right)^{k_{c}}}\right)
$$

The $\gamma_{c}$ value is determined experimentally (Figure 2). The $\mathrm{W}$-oriented cells start to collapse at about $\gamma_{c}^{W}=0.018$, unfortunately there are no data available for the $\mathrm{L}$ direction. The rest of the values are chosen to fit the experimental curves (see Table 1).

\subsection{Superposition of the initial buckling and the collapse of the cells}

Now that both initial buckling and collapse stages are represented with a damage variable, it would be logical to superpose them to describe the overall response of the structure. This is done through Eq. (3).

The values of Table 1 allow the overall nonlinear behavior of the honeycomb structure under shear stress to be reproduced with good correlation (Figure 7).

$$
\tau=G \gamma\left(1-D_{b}\right)\left(1-D_{c}\right)
$$

The decoupling of the buckling and collapse stages in the shear response of the honeycomb allows the two phenomena to be identified separately. This is very useful as it enables the condition of the cells to be categorized in very clear stages: elastically buckled, buckled with damage, or even collapsed. All of this is achieved very simply.

Both buckling and collapse stages are represented by probability distributions and the values that are chosen to fit the experimental results may not be the only possible combination. However, the parameters with physical meaning, such as the start of buckling or collapse, or even the shear stiffness reductions, are determined experimentally or through numerical analysis, so they should be consistent. The rest of the parameters selected to fit the experimental curves $\left(\lambda_{b}\right.$ and $k_{b}$ ) have a statistical meaning that can be interpreted by looking at the shape of their density distribution functions, Eqs. (4) and (5), for the buckling and the collapse stage respectively.

$$
\begin{aligned}
\text { Density of } D_{b} & =\frac{k_{b}}{\lambda_{b}}\left(\frac{\gamma-\gamma_{b}}{\lambda_{b}}\right)^{k_{b}-1} e^{-\left(\frac{\gamma-\gamma_{b}}{\lambda_{b}}\right)^{k_{b}}} \\
\text { Density of } D_{c} & =\frac{k_{c}}{\lambda_{c}}\left(\frac{\gamma-\gamma_{c}}{\lambda_{c}}\right)^{k_{c}-1} e^{-\left(\frac{\gamma-\gamma_{c}}{\lambda_{c}}\right)^{k_{c}}}
\end{aligned}
$$

The shape of the probability density that represents the initial buckling $(k=1)$ suggests that the cells suddenly buckle at $\gamma_{b}^{W}=0.0096$ but then the buckling rate becomes almost constant (Figure 8). This indicates that, at the scale of the specimen, the buckling of the cell walls may not be very sensitive to the initial defects. In other words, the cell buckling is averaged at a similar shear stress or $\gamma$ regardless of the initial defects of each cell.

Regarding the distribution of the collapse of the cells, the shape of the density function $(k=1.9$ or 1.45$)$ suggests that some of the cells collapse earlier and some later (as expected). This could mean that this stage is more sensitive to the initial defects (Figure 8), especially when the cells are loaded in the W direction.

\section{Numerical modeling using the proposed approach}

The next step is to implement the CDM approach presented into a F.E. model. For this, the honeycomb is represented only with volume elements, as if it were an orthotropic material. 


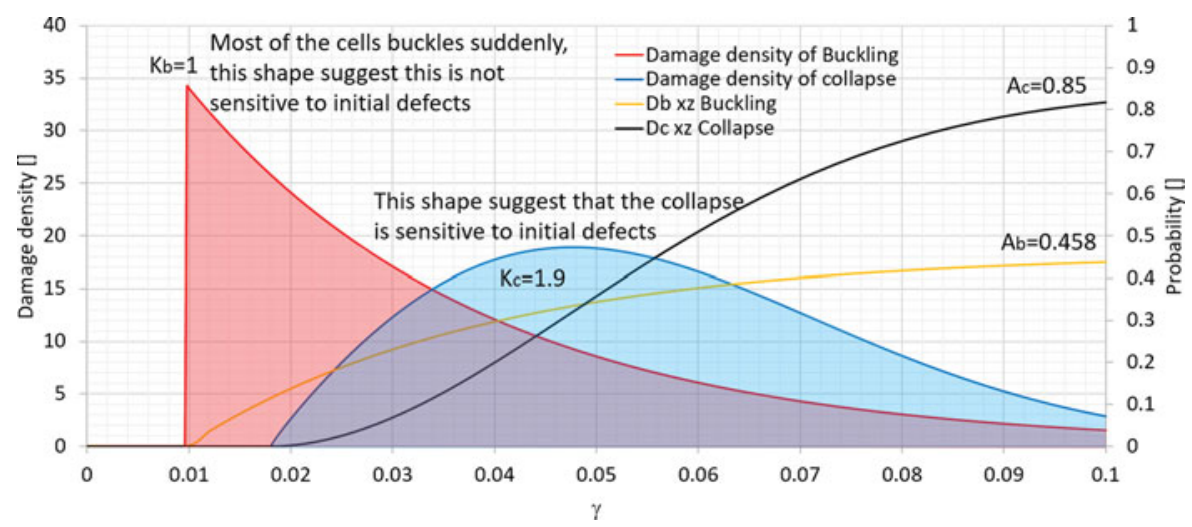

Figure 8. Density distribution curves that represents the buckling and collapse of the cells stages.

However, since the honeycomb core presents a softening behavior after the collapse of the cells, there can be undesired damage localization depending on the size of the mesh. To avoid this effect, the core is represented with only one element of thickness (C3D8) and the length and width of the elements are adjusted to the radius of the honeycomb alveolus.

The desired damage laws are implemented in a UMAT subroutine. To take the nonlinear elastic behavior of the honeycomb core into consideration, the damage activation function records the damage only after the nonlinear elastic limit is reached. As the nonlinear behavior of the double rail and potting beam specimens are different for the collapse stage, the two models are presented separately.

\subsection{Double rail test specimen}

For this specimen (Figure 9), the skins were made of aluminium $(\mathrm{E}=75000 \mathrm{MPa})$ having a thickness of $5 \mathrm{~mm}$. The core was glued to the skins using Redux 609 epoxy film and therefore, in the simulations, the pieces are bonded using a tie constraint.

The core was oriented in the $\mathrm{W}$ direction. To model the HRH-78 Nomex honeycomb core, the data from [22] and the orthotropic mechanical properties given by the manufacturer are used; $E_{\mathrm{z}}=125 \mathrm{MPa}, v_{\mathrm{W}}=0.02, v_{\mathrm{L}}=0.02, G_{\mathrm{W}}=$ $24 \mathrm{MPa}$, and $G_{\mathrm{L}}=32 \mathrm{MPa}$. Also, it is considered that the honeycomb remains undamaged until $\gamma_{\mathrm{W}}=0.024$ and $\gamma_{\mathrm{L}}=0.023$ for the $\mathrm{W}$ and $\mathrm{L}$ directions, respectively. The values of Table 1 are used to include the buckling and collapse of the cells for the shear

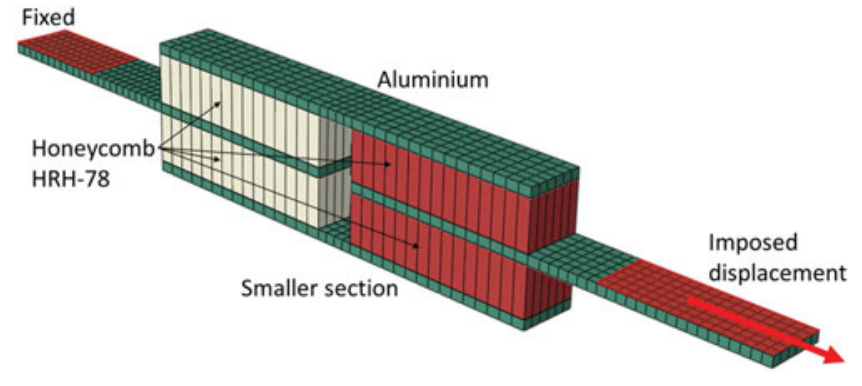

Figure 9. Meshing of the double rail test model.

stiffness reduction. Finally, a cyclic displacement is imposed in the finite element model, this consists of increments of $0.25 \mathrm{~mm}$ each until $2.5 \mathrm{~mm}$ is reached. The numerical and experimental results are compared in Figure 10.

The time step is $1 \mathrm{~s}$, the maximum increment is $0.001 \mathrm{~s}$, and the required number of increments is 1031 . The simulation run used 8 CPUs and took 12 min $34 \mathrm{~s}$. There were some convergence issues when the negative slope of the material of the core started to appear. Nevertheless, the results show good agreement with the experiments.

\subsection{Three-point test with lateral stabilization specimen}

For the sandwich beam stabilized test (Figure 11), the skins were made of two plies of G9389 (carbon tissue/epoxy) with a total thickness of $0.55 \mathrm{~mm}$, the core and the skins were glued using the

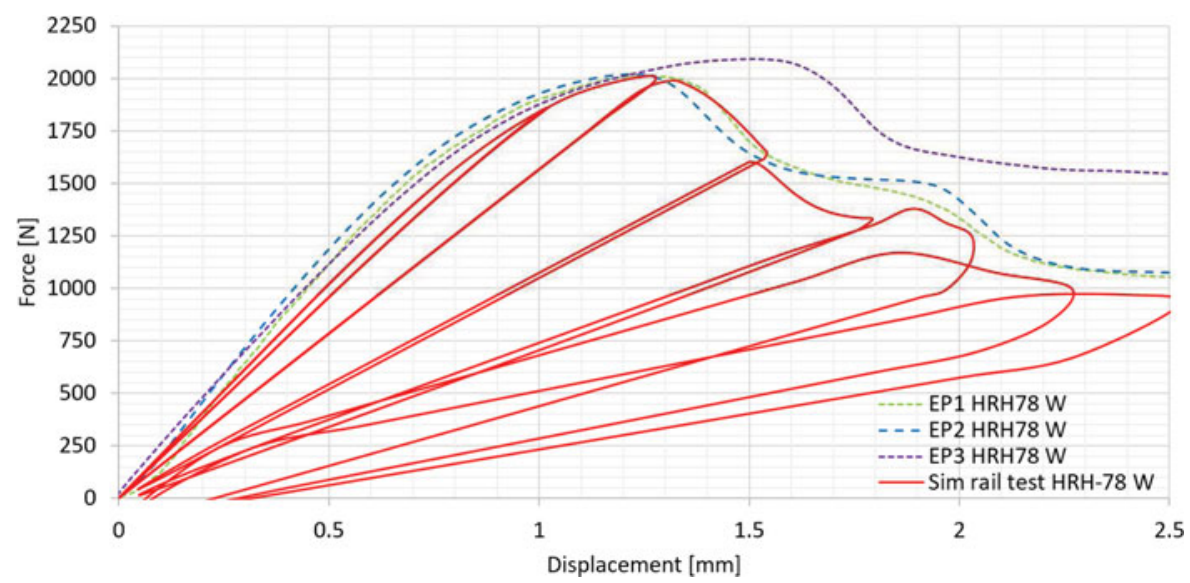

Figure 10. Force vs. displacement curves of the double rail tests: Experimental (dashed lines) vs. numerical results. 


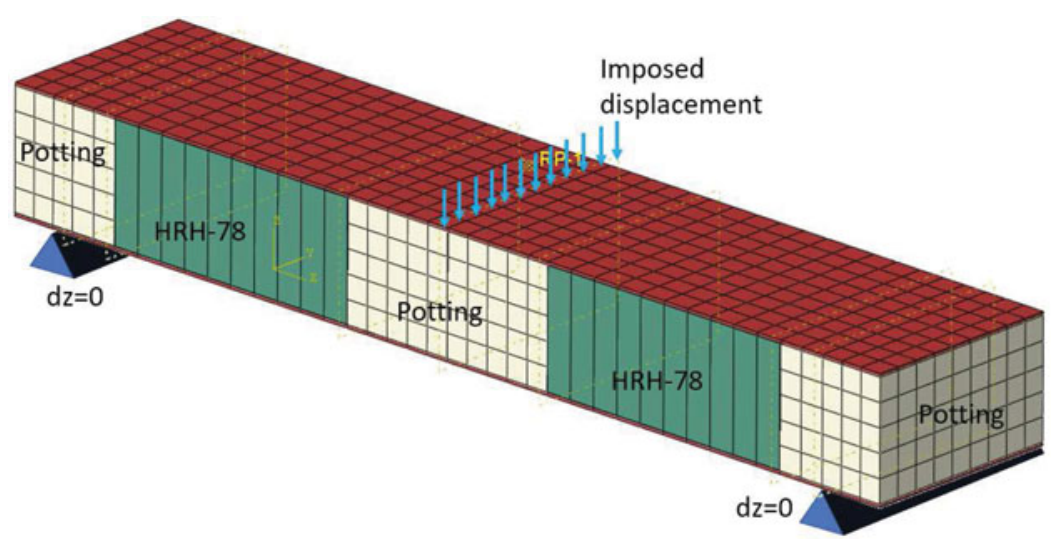

Figure 11. Meshing of the sandwich beam with potting at the borders.

same adhesive as used in the rail tests. The potting was made of Araldite AV- $121 \mathrm{~N}$ mixed with $10 \%$ of ponderal weigh phenolic microspheres $(E=1312 \mathrm{MPa})$. The core was oriented in the $\mathrm{L}$ direction. More information is available in [1].

The same orthotropic stiffness values were used for the core as for the rail tests. Since the boundary conditions were different, the general nonlinear response should be different too.

Unfortunately, there is no experimental reference for the nonlinear elastic limit so it was taken to be the same as for the rail test.

According to [1], the lateral stabilization provided by the potting on the HRH-78 causes several differences that should be taken into consideration.

The period of linear behavior of the honeycomb structure is increased, so the collapse does not just occur later than in the rail tests; it is also more dramatic.

By using the proposed CDM approach, it is possible to modify only the collapse parameters to fit the experimental results. The collapse initiation is set to appear later than for the rail tests, at $\gamma_{c}^{L}=0.039$. The effect of the dramatic collapse is included by selecting a small-scale parameter $\lambda_{c}^{L}=0.005$. The resulting behavior law is shown in Figure 12.

Unfortunately, the proposed law causes convergence problems when the simulation is run. This is because of the very pronounced negative slope at the collapse of the cells, a common problem when an implicit solver is used.

To avoid this, another technique is used to reproduce the desired curve. The initial behavior of the cells is fitted without considering their dramatic collapse. Finally, when $\gamma_{c}^{L}=0.044$ is reached, the shear stiffness is reduced to $10 \%$ to simulate the dramatic collapse of the cells, which may be equivalent to choosing a small-scale parameter $\lambda_{c}^{L}$ as intended before (see Figure 13). This technique is widely used as it represents the loss of stiffness and maintains a positive slope on the behavior of the material, avoiding the problems of convergence created by the negative slopes. The values that are used for the alternative approach (Figure 13) are shown in Table 2.
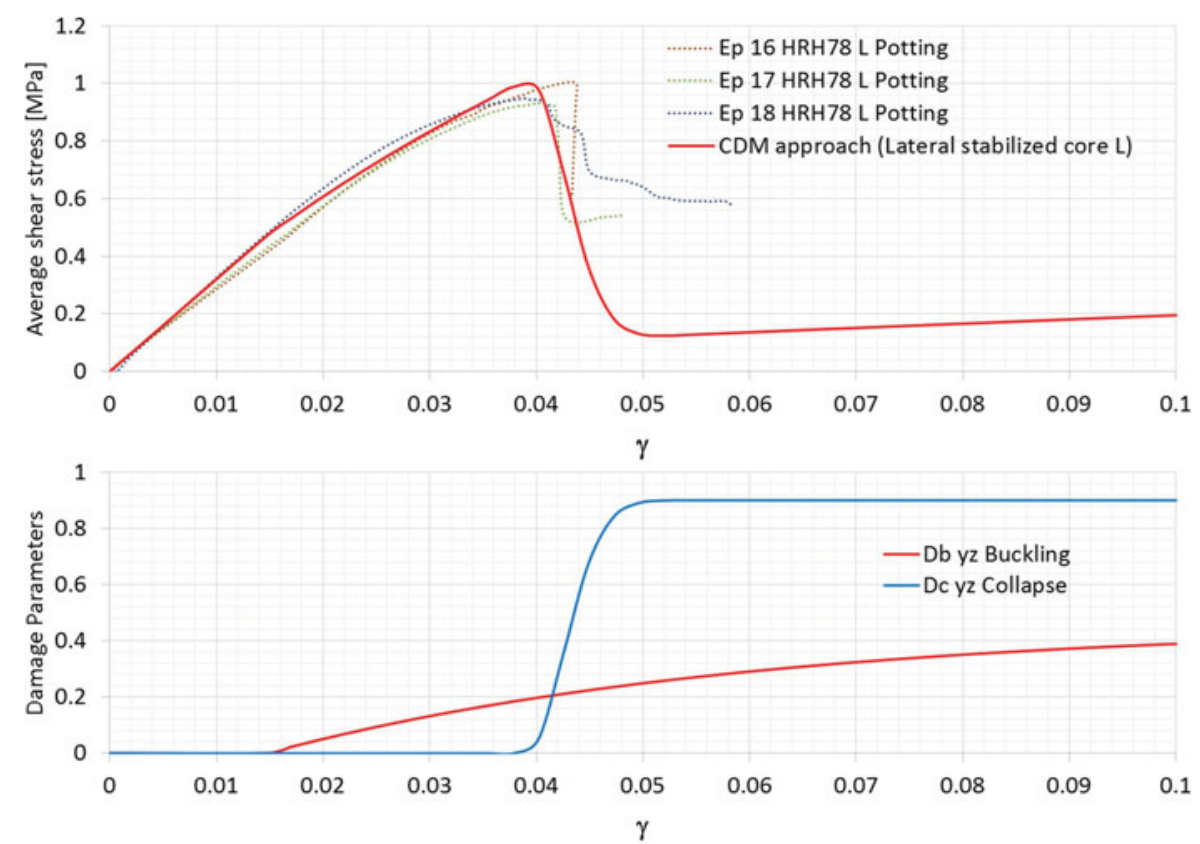

Figure 12. Fitting of the experimental sandwich beam tests in the $L$ direction with potting at the border using the proposed CDM approach (creates convergence issues). 

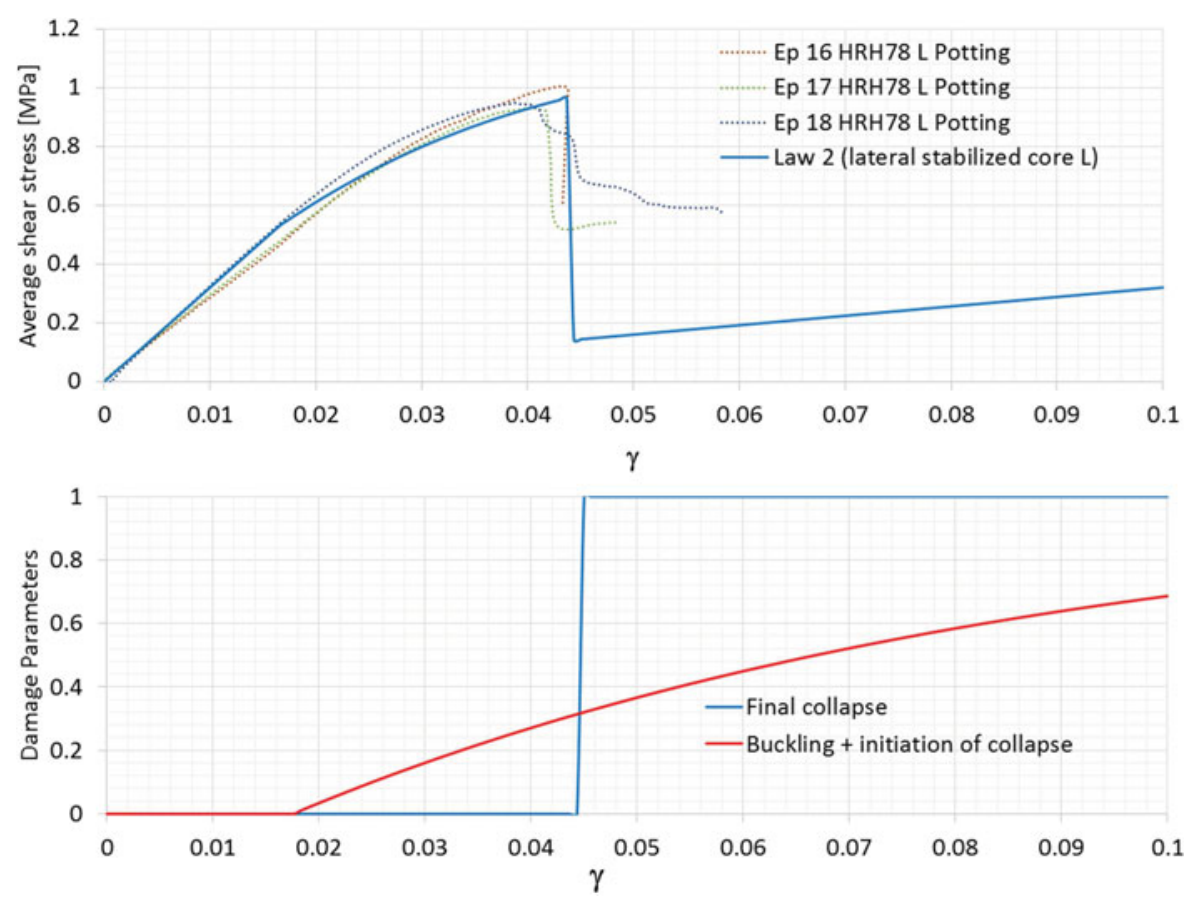

Figure 13. Fitting of the tests of experimental sandwich beam with potting at the border in the $L$ direction with an alternative approach (without convergence issues).

Table 2. Values used to fit the experimental curves of the HRH-78 three point bending tests with lateral stabilization.

\begin{tabular}{|c|c|c|c|}
\hline & & W direction & $\mathrm{L}$ direction \\
\hline \multirow[t]{5}{*}{ Law 1 (Non lateral stabilized core) } & A & 1 & 1 \\
\hline & $\lambda_{b}$ & 0.04 & 0.044 \\
\hline & $\gamma_{\mathrm{b} 0}$ & 0.0096 & 0.014 \\
\hline & $k_{b}$ & 1 & 1 \\
\hline & $\gamma_{c 0}^{0}$ Final collapse & 0.038 & 0.044 \\
\hline \multirow[t]{5}{*}{ Law 2 (Lateral stabilized core) } & $A^{\mathrm{CO}}$ & 0.6 & 0.55 \\
\hline & $\lambda_{b}$ & 0.025 & 0.03 \\
\hline & $\gamma_{\mathrm{b} 0}^{0}$ & 0.017 & 0.017 \\
\hline & $k_{b}$ & 1 & \\
\hline & $\gamma_{c 0}$ Final collapse & 0.038 & 0.044 \\
\hline
\end{tabular}

A comparision was made between the experimental and numerical results of the testing of the sandwich beam specimens. In Figure 15, the force versus displacement curves are compared and show good agreement even for the nonlinear behavior. The failure scenarios of the numerical and experimental results are also very similar (see Figure 14), proving that this technique gives good results.
The time step is $1 \mathrm{~s}$, the maximum increment is $0.01 \mathrm{~s}$, and the required number of increments is 105 . The simulation was run on 8 CPUs and lasted for $2 \mathrm{~min} 25 \mathrm{~s}$. In general, the results show good agreement with the experiments.

\subsection{Discussion of the modeling strategy for both specimens.}

The behavior laws that were used to represent the shear behavior or the HRH-78 honeycomb core for the double rail tests and the sandwich beam with potting were very different. Initially, the behavior was identical in both cases but the collapse stage was very different. It seems that the laterally stabilized cells follow the path of the case when the cells are totally elastic, until they collapse at $\gamma_{c}^{L}=0.039$ (Figure 16).

This makes it clearer that the boundary conditions are very important for the honeycomb core, especially since one of the resulting effects is that the shear strength is increased. This is important because ignoring this effect could lead to oversizing of the structure.

To show this, the model of the sandwich beam with lateral stabilization is considered again, but using another damage law

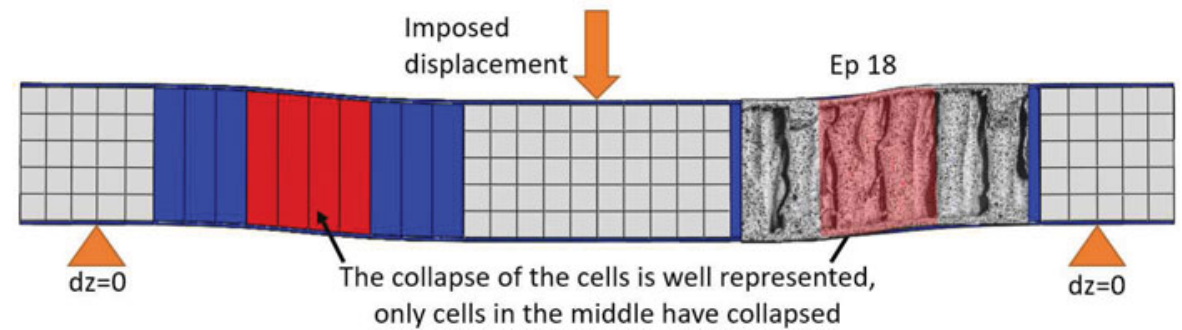

Figure 14. Comparison of the failure scenario of the numerical model vs. real tests; the results are consistent. [1]. 


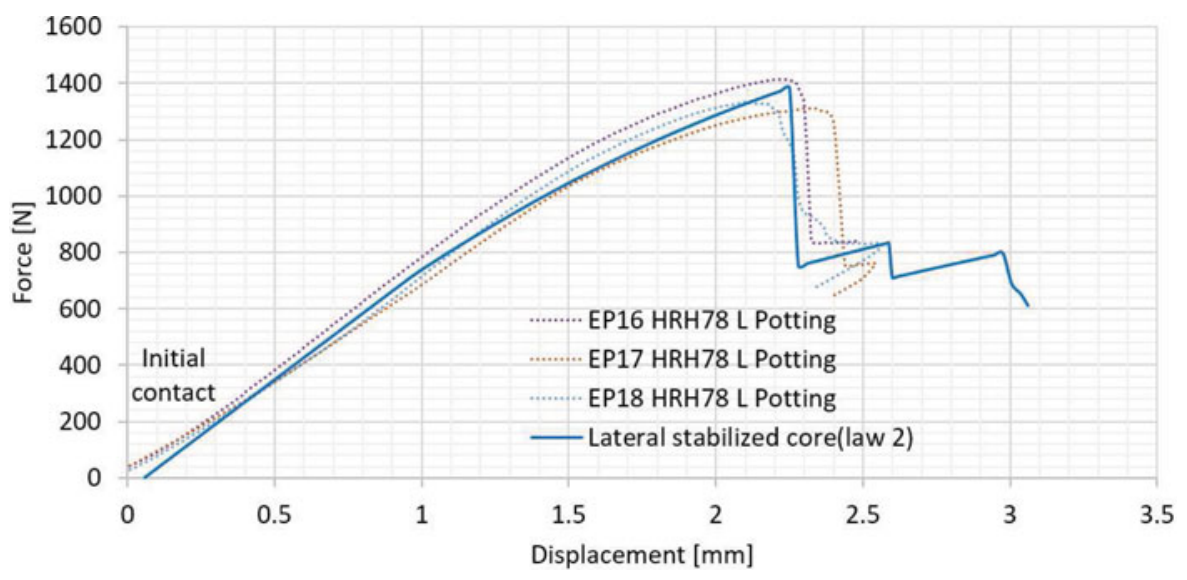

Figure 15. Force vs. displacement curves of the sandwich beam tests: Experimental vs. numerical results.

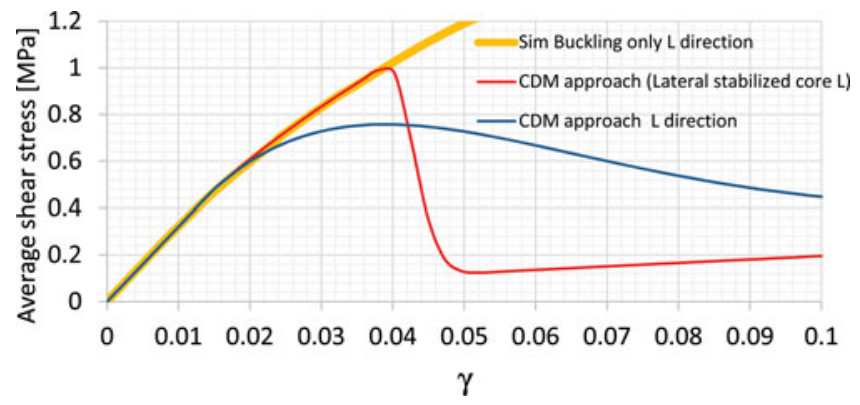

Figure 16. Force vs. displacement curves of the sandwich beam tests: Experimental vs. numerical results.

to model the shear behavior of the honeycomb core. In this case the law represents the behavior that the core should have without considering the increase in the shear strength (due to the lateral stabilization on the honeycomb). A comparison of the two laws and the results are shown in Figure 17.

It is important to mention that the simulation time required for these models is very short in comparison with refined models. The detailed model presented in [1] consisted of only 8 alveoli but the time required to simulate an imposed displacement of $1 \mathrm{~mm}$ in the L direction was $3.28 \mathrm{~h}$. (197 min.). In comparison, for the double rail model, 300 alveoli were represented using the approach proposed here and a total displacement of $27.5 \mathrm{~mm}$ was imposed on the specimen. The simulation time required was only $12.5 \mathrm{~min}$.

\section{Conclusions}

This strategy enables a set of different physical effects related to the buckling and collapse stages of the cells to be represented in a very simple and practical way. As explained in [1], the nonlinear behavior of the honeycomb structure presents a nonlinear elastic behavior beyond the buckling point of the cells but the shear strength can be increased by stabilizing the cells laterally. This is explained by reversible postbuckling as in aerospace structures.

The inclusion of this feature in sandwich panel design should be interesting as it reduces the weight. Also, it can be of interest for inserts, as they are designed using analytical formulas that are based on the shear strength of the honeycomb core.

One of the advantages of the modeling strategy presented is that it allows the nonlinear effects of the honeycomb structure, such as the buckling and collapse of the cells, to be included for a very low computational cost, and also enables the collapse of cells to be easily identified so as to avoid it. This is very interesting in comparison with the very detailed models that can be found in the related literature or for large, refined models of honeycomb panels, where every cell should be inspected to determine whether it is damaged or collapsed, which can take a lot of time. [8], [12]

Another advantage is that it requires less expertise, and so the costs of the embodiment design stage are decreased, as the computational and development times can be reduced dramatically.

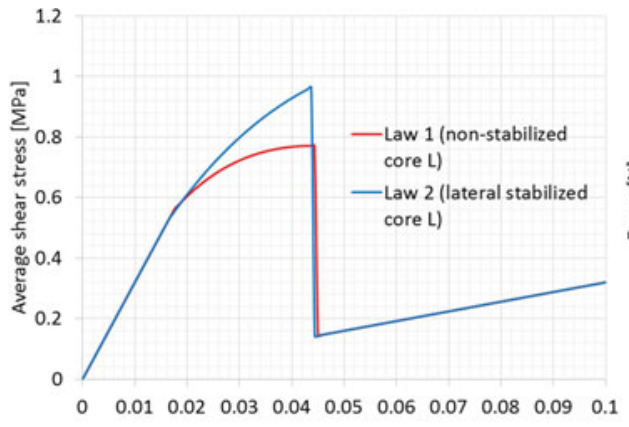

$\gamma$

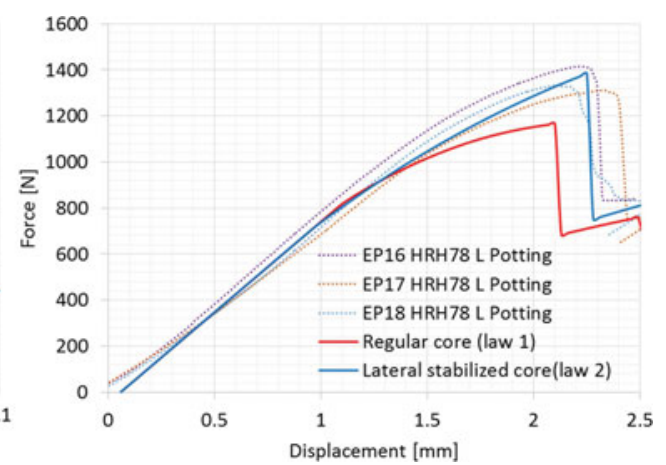

Figure 17. Two different laws are used to model the shear behavior of the HRH-78 cells, with and without the effect of the lateral stabilization of the cells. 
The proposed approach is supported by several observations made after a very detailed analysis of the shear behavior of the honeycomb core. It is interesting to mention that the inclusion of probability functions allows the average general behavior of this type of cellular structure to be described well.

The assumption of using only one element on the thickness helped to reduce the simulation time and also to include the post buckling softening behavior of the honeycomb structure, avoiding the damage localization problem. This feature is very debatable. The main drawback is that it excludes the possibility of studying the buckling of the cell walls or collapse of the cells in detail, as the honeycomb structure is replaced by an orthotropic virtual material. However, from a practical point of view, obtaining a detailed description of the buckling or the collapse shape of the cells is not the main preoccupation in most cases, e.g. when large models are being simulated.

However, it is indeed important to include the nonlinear behavior of the honeycomb structure, as well as to be able to know whether cells have collapsed or not. Thus, this approach can be considered as a shortcut to include the nonlinear behavior of the honeycomb structure without having to invest considerable computing and development time to observe features that, at the end of the day, are irrelevant for the analysis (such as the exact shape of the cells when they buckle or collapse).

The next steps of this approach are to develop a plate damage model to take the off-axis nonlinear postbuckling into account and to combine it with the nonlinear compression response.

\section{Acknowledgments}

The present work was supported in part by the Mexican government, through the program "Becas Conacyt- Gobierno Frances", and by the "Institut Clément Ader". This support is acknowledged with thanks. The authors also wish to thank SOGECLAIR Aerospace for its support, and especially M. J.P. Giavarini and M. Deloubes.

\section{References}

[1] J. de D. Rodríguez Ramírez, B. Castanié, and C. Bouvet, "Experimental and numerical analysis of the shear nonlinear behavior of the Nomex honeycomb core: application to insert sizing," Compos. Struct., vol. 193, pp. 121-139, 2018. DOI: 10.1016/j.compstruct.2018.03.076.

[2] D. ZenKert, The Handbook of Sandwich Construction. Emas, London, UK, 1997.

[3] B. Castanié, J. J. Barrau, J. P. Jaouen, and S. Rivallant, "Combined shear/compression structural testing of asymmetric sandwich structures," Exp. Mech., vol. 44, no. 5, pp. 461-472, 2004. DOI: 10.1007/BF02427957.

[4] C. Kassapoglou, Design and Analysis of Composite Structures: With Applications to Aerospace Structures. Wiley, Chichester, UK, 2011.

[5] D. Gay, S. V. Hoa, and S. W. Tsai, Composite Materials: Design and Applications. Taylor \& Francis, Boca Raton, FL, USA, 2002.
[6] R. K. Mc Farland, "Hexagonal cell structures under post-buckling axial load," AIAA J., vol. 1, no. 6, pp. 1380-1385, 1963. DOI: 10.2514/3.1798.

[7] T. Wierzbicki, "Crushing analysis of metal honeycombs," Int. J. Impact Eng., vol. 1, no. 2, pp. 157-174, 1983. DOI: 10.1016/0734743X(83)90004-0.

[8] R. Seemann and D. Krause, "Numerical modeling of nomex honeycomb sandwich cores at meso-scale level," Compos. Struct., vol. 159, pp. 702-718, 2017. DOI: 10.1016/j.compstruct.2016.09.071.

[9] F. H. C. Fischer, A. Hauffe, and K. Wolf, "Influence of imperfections on the structural behavior of honeycomb cores," presented at ECCM17 - 17th European Conference on Composite Materials Munich, Germany, 26-30th Jun. 2016.

[10] B. Castanié, Y. Aminanda, C. Bouvet, and J.-J. Barrau, "Core crush criterion to determine the strength of sandwich composite structures subjected to compression after impact," Compos. Struct., vol. 86, no. 1-3, pp. 243-250, 2008. DOI: 10.1016/j.compstruct.2008.03.032.

[11] Y. Aminanda, B. Castanié, J.-J. Barrau, and P. Thevenet, "Experimental analysis and modeling of the crushing of honeycomb cores," Appl. Compos. Mater., vol. 12, pp. 213-227, 2005. DOI: $10.1007 / \mathrm{s} 10443-$ 005-1125-3.

[12] D. Asprone et al., "Statistical finite element analysis of the buckling behavior of honeycomb structures," Compos. Struct., vol. 105, pp. 240-255, 2013. DOI: 10.1016/j.compstruct.2013.05.014.

[13] P. Bunyawanichakul, B. Castanié, and J.-J. Barrau, "Non-linear finite element analysis of inserts in composite sandwich structures," Compos. Part B Eng., vol. 39, no. 7-8, pp. 1077-1092, Oct. 2008. DOI: 10.1016/j.compositesb.2008.05.004.

[14] S. Heimbs and M. Pein, "Failure behavior of honeycomb sandwich corner joints and inserts," Compos. Struct., vol. 89, no. 4, pp. 575-588, 2009. DOI: 10.1016/j.compstruct.2008.11.013.

[15] R. Roy, K. H. Nguyen, Y. B. Park, J. H. Kweon, and J. H. Choi, “Testing and modeling of Nomex ${ }^{\mathrm{TM}}$ honeycomb sandwich Panels with bolt insert," Compos. Part B Eng., vol. 56, pp. 762-769, 2014. DOI: 10.1016/j.compositesb.2013.09.006.

[16] M. Giglio, A. Gilioli, and A. Manes, "Numerical investigation of a three point bending test on sandwich panels with aluminum skins and Nomex ${ }^{\mathrm{TM}}$ honeycomb core," Comput. Mater. Sci., vol. 56, pp. 69-78, 2012. DOI: 10.1016/j.commatsci.2012.01.007.

[17] M. Giglio, A. Manes, and A. Gilioli, "Investigations on sandwich core properties through an experimental-numerical approach," Compos. Part B Eng., vol. 43, no. 2, pp. 361-374, Mar. 2012. DOI: 10.1016/j.compositesb.2011.08.016.

[18] L. Liu, P. Meng, H. Wang, and Z. Guan, "The flatwise compressive properties of Nomex honeycomb core with debonding imperfections in the double cell wall," Compos. Part B Eng., vol. 76, pp. 122-132, 2015. DOI: 10.1016/j.compositesb.2015.02.017.

[19] B. Castanié, C. Bouvet, Y. Aminanda, J. J. Barrau, and P. Thevenet, "Modelling of low-energy/low-velocity impact on Nomex honeycomb sandwich structures with metallic skins," Int. J. Impact Eng., vol. 35, no. 7, pp. 620-634, 2008. DOI: 10.1016/j.ijimpeng.2007.02. 008.

[20] A. Kolopp, R. A. Alvarado, S. Rivallant, and C. Bouvet, "Modeling impact on aluminium sandwich including velocity effects in honeycomb core," J. Sandw. Struct. Mater., vol. 15, no. 6, pp. 733-757, 2013. DOI: $10.1177 / 1099636213501102$.

[21] E. J. Barbero, Finite Element Analysis of Composite Materials using AbaqusTM. Abington, UK, 2013.

[22] HexWeb, "HexWeb Honeycomb Attributes and Properties," 1999. 